\title{
Combined Influence of Organic Additives on Growth Morphology of Calcium Carbonate
}

\author{
BALAKRISHNA KURRA and SARATCHANDRA BABU MUKKAMALA* \\ Department of Chemistry, GITAM University, Visakhapatnam - 530 045, A.P., India. \\ *Corresponding author E-mail: mscbabu@yahoo.com
}

http://dx.doi.org/10.13005/ojc/290437

(Received: September 10, 2013; Accepted: November 19, 2013)

\begin{abstract}
The influence of organic additives, $\beta$-cyclodextrin, HEDTA, L-aspartic acid and L-glutamic acid on crystal growth of calcium carbonate via vapour diffusion method has been investigated. In the absence of additive, regular rhombohedral calcium carbonate crystal habit resulted. Whereas in presence of additive, calcite with truncated, aggregated rhombohedral sub crystals and elongated hexagonal morphologies resulted. The obtained calcium carbonate phases were characterized by SEM, Powder XRD and FT-IR.
\end{abstract}

Key words: Biomineralisation, Calcium carbonate, $\beta$-cyclodextrin, HEDTA, L-glutamic acid, L-aspartic acid.

\section{INTRODUCTION}

The aesthetic control over structures and properties of biominerals produced in nature inspired chemists, biologists and materials scientists since a long time $e^{1-3}$. Mimicking the design and synthesis of biominerals by living organisms is the current challenge for scientists ${ }^{4-10}$. Calcium carbonate is among the most studied biominerals because of its high abundance and ubiquity in nature. It is well established now that in case of calcium carbonate biominerals, templates with carboxylate groups are likely to direct structure through carboxylate moieties occupying carbonate sites during crystal growth and thereby directing the structure to produce the desired shape and functionality ${ }^{11,13}$. Our previous works have shown that by varying the concentration, it is possible to synthesize different polymorphs of calcium carbonate using dicarboxylic acids such as malonic acid, succinic acid etc as templating agents $^{13-14}$. Another polycarboxylate was employed to synthesize calcite-micro trumpets ${ }^{14-16}$ which closely mimic the coccoliths of an unicellular algae, Discosphaera tubifera. In nature, living organisms use a organic matrix containing mixed functionalities for controlling the growth, size and morphology of biominerals. Hence we have attempted to investigate the influence of mixed additives such as $\beta$-cyclodextrin ( $\beta-C D), \mathrm{N}$-(2-hydroxyethyl) ethylene diamine-N,N',N'-triaceticacid (HEDTA), L-aspartic acid (L-ASP) and L-glutamic acid (L-GLU) (Scheme 1) on growth morphology of calcium carbonate and reported in this paper. 


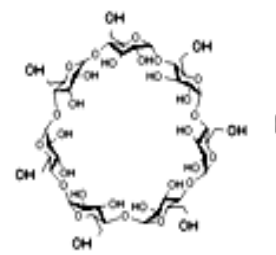

(a)<smiles>O=C(O)CN(CCO)CCN(CCO)CC(=O)O</smiles>

(b)<smiles>NC(CC(=O)O)C(=O)O</smiles>

(c)<smiles>NC(CCC(=O)O)C(=O)O</smiles>

(d)

\section{Scheme 1: (a) $\beta$-cyclodextrin (b) N-(2-hydroxyethyl) ethylene diamine-N,N',N'-triaceticacid (c) L-aspartic acid (d) L-glutamic acid}

\section{EXPERIMENTAL}

\section{Materials}

All chemicals were of analytical grade and used without any further purification. $\mathrm{CaCl}_{2} \cdot 2 \mathrm{H}_{2} \mathrm{O}$, $\left(\mathrm{NH}_{4}\right)_{2} \mathrm{CO}_{3}$, L-aspartic acid, L-glutamic acid and $\mathrm{NaOH}$ were obtained from Merck, $\mathrm{N}$-(2-Hydroxyethyl) ethylenediamine-N,N',N',-triaceticacid (HEDTA) and $\beta$ - cyclodextrin $(\beta-C D)$ were obtained from SigmaAldrich and Himedia chemicals, respectively.

\section{Synthesis}

The mineralization of calcium carbonate was carried out by a slow $\mathrm{CO}_{2}$ gas diffusion method. $0.1136 \mathrm{~g} \beta-\mathrm{CD}(0.1 \mathrm{mmol})$ taken along with the $0.147 \mathrm{~g} \mathrm{CaCl}_{2} \cdot 2 \mathrm{H}_{2} \mathrm{O}(1.0 \mathrm{mmol})$ in a glass beaker containing $10 \mathrm{ml}$ distilled water and dissolved the solids by stirring thoroughly with the help of magnetic stirrer. Then the $\mathrm{pH}$ of the solution was adjusted to 7.0 with the help of dil. $\mathrm{NaOH}$. The final solution was transferred into the cell culture dish and covered with parafilm. 2 to 3 holes were made on parafilm and placed in the top chamber of dessicator. Carbon dioxide released from ammonium carbonate, placed in the bottom chamber of dessicator, entered into reaction mixture. After 24 hours at $25 \pm 1^{\circ} \mathrm{C}$, crystals were filtered, washed with distilled water and dried in dessicator. Same experimental procedure was followed for the influence of HEDTA, L-asparticacid and L-glutamic acid. In place of $0.1 \mathrm{mmol} \beta-C D$, $0.0278 \mathrm{~g}$ HEDTA $(0.1 \mathrm{mmol})$ or $0.0133 \mathrm{~g}$ L-ASP $(0.1$ $\mathrm{mmol})$ or $0.0147 \mathrm{~g} \mathrm{L-GLU}(0.1 \mathrm{mmol})$ was taken for the crystallization of calcium carbonate in presence of these additives. To examine the mineralization of calcium carbonate in presence of combined additives, $0.1 \mathrm{mmol} \beta-\mathrm{CD}$ ) with $0.1 \mathrm{mmol}$ HEDTA/0.1 $\mathrm{mmol}$ L-ASP $/ 0.1 \mathrm{mmol} \mathrm{L}-\mathrm{GLU}$ were mixed in place of single additive.

\section{Characterization methods}

Perkin-Elmer Spectrum Two FT-IR Spectrometer and PANALYTICAL X'Pert pro powder diffractometer system operating with monochromated $\mathrm{Cu} \mathrm{K} 1$ radiation were used for phase characterization. FEI Quanta 200 FEG with EDS scanning electron microscope was used to obtain the SEM images.

\section{RESULTS AND DISCUSSIONS}

\section{Morphology}

It was observed that the thermodynamically most stable calcite rhombohedral phase formed exclusively in control experiments i.e., without using any additive (Fig. 1). The shape and phase controlling influence of the additive on the formation of $\mathrm{CaCO}_{3}$ has been investigated at different molar ratios of $\left[\mathrm{Ca}^{2+}\right] /[$ additive $]$ at $50,20,10$ at room temperature $21.0 \pm 1^{\circ} \mathrm{C}$ at solution $\mathrm{pH} 7.0$. But best resulted obtained at $\left[\mathrm{Ca}^{2+}\right] /[$ additive $]=10$ were presented in this paper.

Polysaccharides are known to control the growth of calcite in coccoliths (unicellular algae) by preferential adsorption onto particular surfaces of the calcite crystal15. Hence, the influence of cyclic polysaccharide, $\beta-C D$ on the crystallisation of calcium carbonate was studied. $\beta-C D$ is a truncated conical molecule with a hollow cavity. Chemically, the cavity and the inside of the cone are hydrophobic and the outside of the cone is hydrophilic. $25-50 \mu \mathrm{msized}$ regular rhombohedral crystals transformed to truncated rhombohedral morphology by the influence of $\beta$-CD (Fig. 2a). Similar effect was observed in case of HEDTA (Fig. 2b). $15 \mu \mathrm{m}$ to $30 \mu \mathrm{m}$ sized rhombohedral sub-crystals on aggregate faces were resulted with the influence of L-ASP(Fig. 2c). 


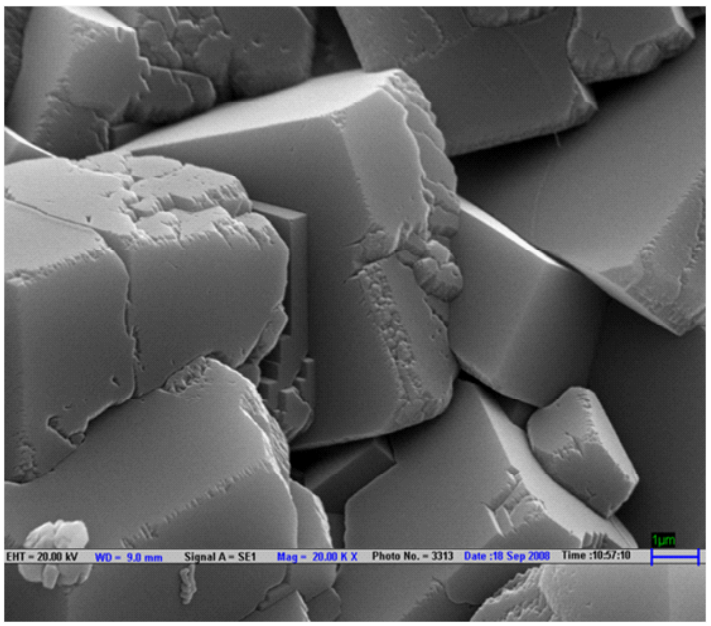

Fig. 1: SEM Image calcite and vaterite phases of calcium carbonate produced in control

It was observed that vaterite also formed in small quantity beside the major calcite phase.Truncated rhombohedral calcite crystals (25-50 $\mu \mathrm{m}$ size) along with more amorphous vaterite resulted with the influence of L-GLU (Fig. 2d).

Further, cooperative influence of $\beta-C D$ with other acidic carboxylate organic moleculeslike HEDTA, L-ASP, L-GLU on the growth morphology of calcium carbonate was investigated. In general, low molecular organic additives make achoice for biomimetic production of $\mathrm{CaCO}_{3}$ minerals. These additives are selectively adsorb on growing faces of minerals and change the morphology. It is important to mention that, the nature and number of acidic functional groups on additive will play a key role in controlling the crystal growth.It was assumed that, mixed component of $\beta-C D$ and HEDTA are adsorbed on to the $\{1-10\}$ faces of calcite and inhibited the growth of these faces, leading to the formation of elongated hexagonal calcite crystals (Fig. $3 a$ and 3b). Similarly $\beta-C D$ with L-ASP directed the formation of truncated rhombohedral calcite with complete agglomeration morphology (Fig. 3c). Again,calcite with rhombohedral sub crystals on aggregate faces resulted with the cooperative influence of $\beta-C D$ and L-GLU on calcium carbonate precipitation (Fig. 3d).

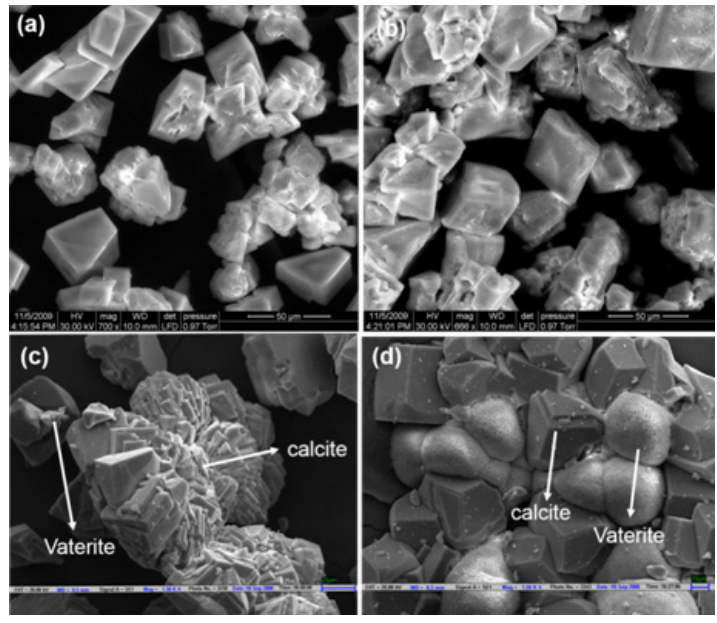

Fig. 2: SEM Images of calcite and vaterite phases of calcium carbonate produced with the influence of $\beta-C D(a), \operatorname{HEDTA}(b)$, L-ASP (c), and L-GLU (d)

\section{$X$-ray diffraction analysis}

The structure and composition of the obtained products was characterized through Powder XRD analysis. XRD patterns of $\mathrm{CaCO}_{3}$ crystals obtained in the absence of additive (control) and in the presence of L-GLU are presented here (Fig. 4). The characteristic diffraction peaks at 23.09, 29.40, $36.00,39.43,43.18$ and 48.52 in XRD spectrum
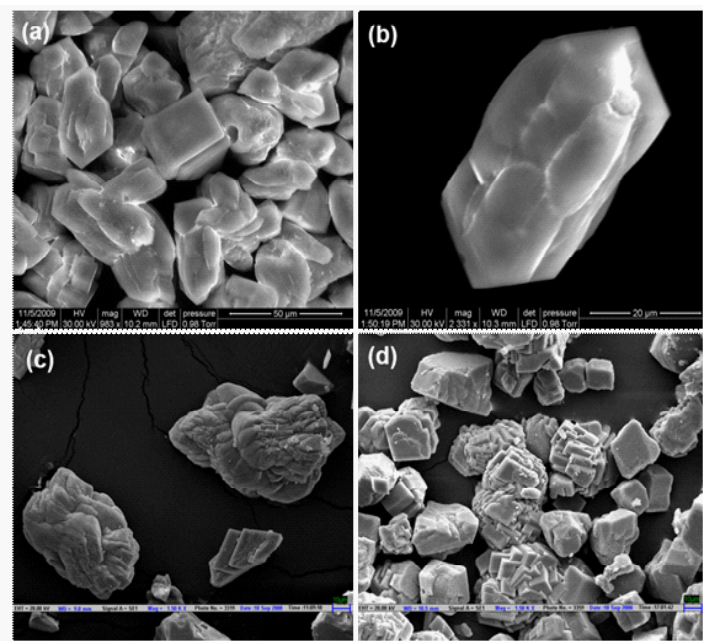

Fig. 3: SEM images of calcite produced with the cooperative influence of (a) $\beta-C D$ and HEDA,

(b) magnified image of calcite crystal (c) $\beta-C D$ and L-ASP, (d) $\beta-C D$ and L-GLU 

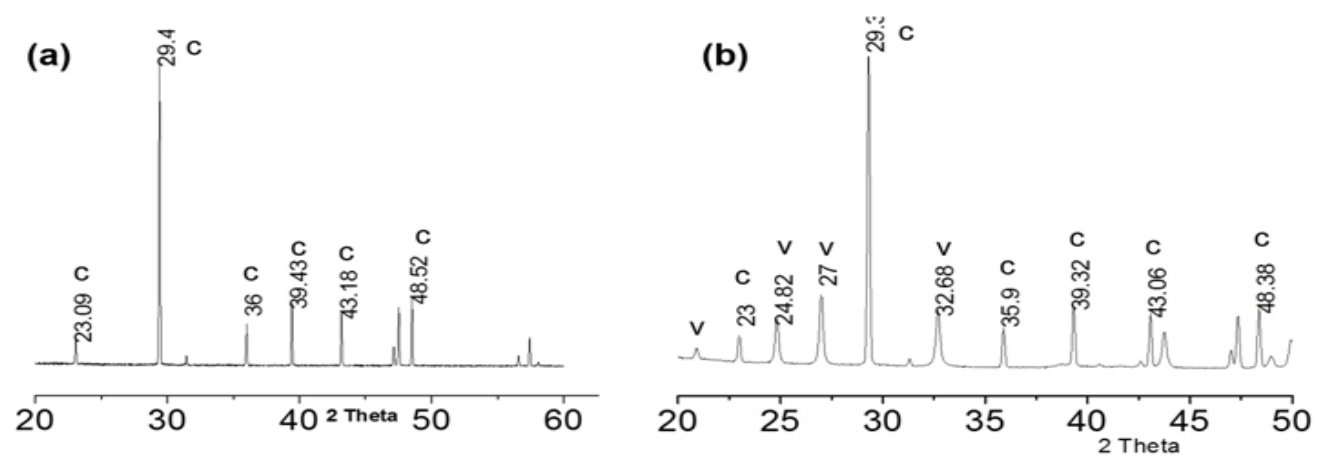

Fig. 4: Powder XRD patterns of (a) $\mathrm{CaCO}_{3}$ produced in control experiments (b) $\mathrm{CaCO}_{3}$ produced in the presence of $\beta-\mathrm{CD}$ and L-GLU (c = calcite, $\mathrm{v}=$ vaterite)
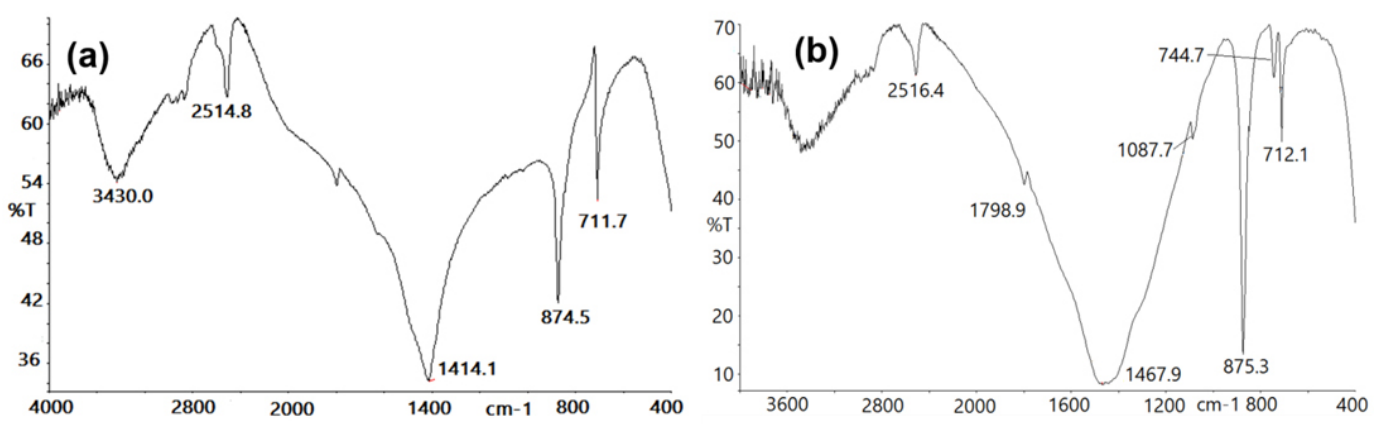

Fig. 5: FT-IR spectrum of (a) $\mathrm{CaCO}_{3}$ produced in control experiments (b) $\mathrm{CaCO}_{3}$ produced in the presence of $\beta-C D$ and L-GLU

indicate the formation of calcite phase (Fig. 4a). As shown in Fig. $4 \mathrm{~b}$ additional diffraction peaks at 21.0, 24.82, 27.0, 32.68 in XRD spectrum indicate the formation of vaterite phase in addition to calcite phase with influence of L-GLU.

\section{IR analysis}

IR analysis of $\mathrm{CaCO}_{3}$ crystals nucleated in the absence of additives is shown in Fig. 5a. The spectrum confirmed the formation of calcite phase with characteristic absorption bands observed at $711.7,874.5$ and $1414.1 \mathrm{~cm}^{-1}$, corresponding to the $v_{4}, v_{2}$ and $v_{3}$ carbonate absorption bands of calcite. Both calcite and vaterite phases were obtained with the influence of L-GLU on crystallization of $\mathrm{CaCO}_{3}$. As shown inFig. 5b, characteristic peaks at 744, 1087 corresponding to the $v 4$ and $v 1$ carbonate absorption bands of vaterite phase of $\mathrm{CaCO}_{3}$.

\section{Probable mechanism of calcium carbonate crystal growth}

A probable mechanism is being proposed for the formation of new calcite crystal morphology under the influence of organic additives. In the initial stage of mineralization, organic additive in the reaction mixture binds with $\mathrm{Ca}^{2+}$ ions on the growing $\mathrm{CaCO}_{3}$ particles and subsequently inhibit the regular array of $\mathrm{Ca}^{2+}$ and $\mathrm{CO}_{3}{ }^{2-}$ required for the formation of mineral. In the next step, additives can influence the growth along $\{104\}$ face and promote the formation of steps and result in truncation and sometimes in the aggregation of crystals.

\section{CONCLUSIONS}

In conclusion, it is noteworthy to mention that the organic additives such as $\beta$-cyclodextrin,

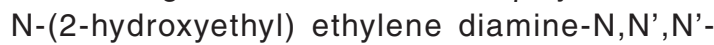


triaceticacid, L-aspartic acid and L-glutamic acid can preferentially attached on the surface of growing phase and influence the morphology of $\mathrm{CaCO}_{3}$. Calcium carbonate with truncated, agglomerated, hexagonal shapes was observed with the influence of the above said additives. Further, the cooperative influence of two additives such as $\beta-C D$ with either HEDTA or L-ASP or L-GLU was investigated.

\section{ACKNOWLEDGEMENTS}

We sincerely acknowledge the SAIF, IIT, Madras for assistance with SEM measurements.

\section{REFERENCES}

1. Mann S., Biomimetic Materials Chemistry, ed. VCH, New York, (1996).

2. Lowenstam H. A. and S. Weiner., On Biomineralization, Oxford University Press, Oxford, (1989).

3. Ozin G. A., Acc. Chem. Res. 30: 17-27 (1997).

4. Dujardin E. and Mann S., Adv. Mater. 14: 775778 (2002).

5. Strohm H. and Loebmann P., J. Mater. Chem. 14: 138-140 (2004).

6. Cheng X., Varona P. L., Olszta M. J. and Gower L. B., J. Cryst. Growth. 307: 395-404 (2007)

7. Li W. and Gao C., Langmur. 23: 4575-4582 (2007).

8. Xu A-W., Ma Y. and Coelfen H., J. Mater. Chem.17: 415-449 (2007).

9. An X. and Cao C., J. Phys. Chem. C. 112: 6526-6530 (2008).
10. Tampieri A., Sandri M., Landi E., Pressato D., Francioli S., Quarto R. and Martin I., Biomaterials. 29: 3539-3546 (2008).

11. Yang J., Liu Y., Wen T., Li Z., Cai Y., Su Y. and Wang D., Cryst. Growth Des. 12: 29-32 (2012).

12. Asenath-Smith E., Li H., Keene E. C., Seh Z. W. and Estroff L. A., Adv. Funct. Mater., 22: 2891-2914 (2012).

13. E. Abbasi and F. Hatamjafari., Orient. J. Chem., 29(2), 731-733 (2013).

14. Mukkamala S. B., Anson C. E. and Powell A. K., J. Inorg. Biochem. 100: 1128-1138 (2006).

15. Mukkamala S. B. and Powell A. K., Chem. Commun. 16: 918-919 (2004).

16. Yang M., Svane Stipp S.L. and Harding J., Cryst. Growth Design. 8: 4066-4074 (2008). 